\title{
Message from the new editorial committee
}

The South African Journal of Radiology has followed a sometimes roller-coaster course in recent times, with issue quality varying widely. This spectrum of quality has largely resulted from lack of a central and consistent editorial voice. In a recent attempt to improve the control and quality of the journal, a number of important changes have been made, starting with the introduction of a full-time Editor-inChief. The first appointed Editor-in-Chief is Ian Duncan. This post will be held for a period of 4 years, and is aimed at ensuring continuity in the running of the journal. The editorial committee has also been changed with immediate effect, and now consists of Professor Coert de Vries (Deputy Editor) (University of the Free State), Professor Leonie Scholtz (University of Pretoria), Professor Darius Tsatsi (MEDUNSA), Dr Savvas Andronikou (University of Cape Town), Professor Peter Corr (University of KwaZulu-Natal), Professor Alan Scher (University of Stellenbosch), Professor Steve Beningfield (University of Cape Town), and Dr Malan van Rensburg (private practice, Pretoria).

The rotating guest editorship will continue. Each academic department will be responsible for one of seven issues, with an eighth 'open' issue completing the 2year cycle. The Head of Department (guest editor) or nominee will canvass articles from staff members, including registrars and radiographers, but should also try and elicit articles from private practices in his or her area. Any article received from any author may be considered for publication by the rotating guest editor in an upcoming issue, regardless of the geographical location of the author(s). It is hoped that each and every senior registrar will produce at least one 
article (at least a case report) before he or she qualifies. This could include publication of MMed theses. To further encourage the submission of articles an annual prize will be awarded for the best articles from a registrar and a qualified radiologist, as judged by the editorial committee. Once the journal is fully accredited with the Department of Education, academic departments will be able to apply for subsidies for each article produced. Another incentive is that CPD points can be awarded for all articles published, with 15 points for the first author and 5 points per co-author. A total of 3 published case reports would thus earn the (first) author nearly all of the required CPD points for a year. Finally there is the Maurice Weinbren award, given each year for the best research paper published by a South African radiologist in the preceding year. This is awarded through the Colleges of Medicine of South Africa.

The $S A J R$ is currently listed with the Department of Education as a locally approved journal (see http://www.education.gov.za/content/documents/ 307.pdf, item no 118). Three basic requirements must be met for a journal to be thus listed: there must be a minimum of 3 issues per year, there must be a suitable editorial committee at the helm, and all articles must be peer-reviewed. All future articles will now undergo blinded peer-review. Reviewers will be invited and may or may not include members of the editorial committee.

The journal could eventually be submitted for international indexing, which if successful would lead to all published articles being listed on Pubmed.

The peer-review process will improve the quality of our publication. One or two senior reviewers will review each article, and the editorial office will inform authors about the progress of the review process. Note that electronic submission of articles will greatly expedite the review process, and that authors will be expected to adhere to the standard publication format (see Instructions for Authors).

Non-reviewed features that will appear will include news items, event and conference listings, pictorial interludes, book reviews, and the CPD questionnaire. A reciprocal arrangement with the South African Medical Journal allows selected articles published in the $S A M J$ to be republished later in the SAJR. Anyone wishing to publish formal research under this arrangement is advised to approach the SAMJ initially.

All qualified radiologists and radiographers, or radiologists- and radiographers-in-training are invited to submit articles for publication in the SAJR. Articles will also be accepted from other sources, provided they are of radiological relevance. Invited and guest editorials will be featured.

All queries concerning the journal can be addressed to: The Editor-in-Chief, SAJR, PO Box 14031, Lyttelton, 0140, E-mail: docdunc2@mweb.co.za

Telephonic enquiries can be made c/o Lizl Geldenhuys at (012) 664-8844.

\section{The Editors}

